\title{
Q Fever, Scrub Typhus, and Rickettsial Diseases in Children, Kenya, 2011-2012
}

\author{
Alice N. Maina, Christina M. Farris, \\ Antony Odhiambo, Ju Jiang, Jeremiah Laktabai, \\ Janice Armstrong, Thomas Holland, \\ Allen L. Richards, Wendy P. O'Meara
}

To increase knowledge of undifferentiated fevers in Kenya, we tested paired serum samples from febrile children in western Kenya for antibodies against pathogens increasingly recognized to cause febrile illness in Africa. Of patients assessed, $8.9 \%, 22.4 \%, 1.1 \%$, and $3.6 \%$ had enhanced seroreactivity to Coxiella burnetii, spotted fever group rickettsiae, typhus group rickettsiae, and scrub typhus group orientiae, respectively.

$\mathrm{R}$ ickettsial diseases, scrub typhus, and Q fever are increasingly recognized as key causes of undifferentiated fevers in humans in Africa (1-6). According to a recent study in western Kenya, respiratory viral infections were responsible for $\approx 41 \%$ of all fevers in children, but $37.1 \%$ were of unknown etiology. In the same study, malaria accounted for $5.2 \%$ of fevers (7). Several attempts have been made to elucidate causes of febrile illnesses in Kenya, but none have focused on causes among children, particularly in settings in which animal husbandry is integrated into communities. To further knowledge of the causes of febrile illnesses in western Kenya, we tested paired acute- and convalescent-phase serum samples from febrile children.

\section{The Study}

Participants were febrile, 1- to 12-year-old children brought for care at Webuye District Hospital (WDH; Bungoma, Kenya). Details of patient recruitment were previously reported (7). In brief, children with fever $\geq 37.5^{\circ} \mathrm{C}$ who lived within the administrative boundaries of Webuye Division were enrolled after informed consent was obtained. Acutephase serum samples were stored at the time of enrollment. Patients returned $\approx 4$ weeks after enrollment for follow-up physical examination and collection of convalescent-phase

Author affiliations: Naval Medical Research Center, Silver Spring, Maryland, USA (A.N. Maina, C.M. Farris, A. Odhiambo,

J. Jiang, A.L. Richards); Moi University College of Health Sciences, Eldoret, Kenya (J. Laktabai, J. Armstrong, W.P. O'Meara); Duke Global Health Institute and Duke University School of Medicine, Durham, North Carolina, USA (T. Holland, W.P. O'Meara)

DOI: http://dx.doi.org/10.3201/eid2205.150953 serum samples. The study protocol was approved by the Moi University Research and Ethics Committee (Eldoret, Kenya), WDH, and the Duke University Institutional Review Board (Durham, North Carolina, USA).

We used ELISAs as described $(5,8-10)$ to evaluate the serum samples for IgG against spotted fever group rickettsiae (SFGR), typhus group rickettsiae (TGR), and scrub typhus group orientiae (STGO). In brief, all convalescent-phase and any unpaired acute-phase serum samples were screened (1:100 dilution), and screen-positive samples were titered in parallel with the corresponding acute-phase samples by serial dilution to assess enhanced seroreactivity to group-specific antigens. Enhanced seroreactivity was defined as a seroconversion from nonreactive in the acute phase to reactive (titer $>400$ ) in the convalescent phase or as a 4-fold rise in antibody titer between acute- and convalescent-phase serum samples. Results for samples that showed enhanced seroreactivity for STGO by ELISA were further confirmed by Western blot, using the recombinant proteins Kpr56 (9) and Kpr47b (5). The Kpr47b Western blot assay was performed as described (5) with the following modifications: Kpr47 antigen was loaded in a Mini-PROTEAN TGX Precast Gel and separated in a Mini Tetra cell electrophoresis module (both from Bio-Rad, Hercules, CA, USA). After being blocked for 1 hour, the membranes were incubated in serum samples diluted 1:100 in 10\% blocking buffer and polyclonal Escherichia coli protein (ratio 1:1). Pierce ECL Plus Western Blotting Substrate (ThermoFisher Scientific, Waltham, MA, USA) was used to develop blots; signal was detected on a ChemiDoc XRS+ System (Bio-Rad).

To screen convalescent-phase serum samples, we used a Coxiella burnetii ImmunoDot assay (GenBio, San Diego, CA, USA) according to the manufacturer's instructions. Samples were diluted 1:200 in the initial stage of this immunoassay.

Data were imported into Stata 11.2 (StataCorp LP, College Station TX, USA) for analysis. We used $\chi^{2}$ tests to compare categorical variables across groups, and we applied $t$-tests for continuous variables; $\mathrm{p} \leq 0.05$ was considered significant.

A total of 370 febrile children were enrolled in the study during November 2011-December 2012. The average age was 4.4 (SD 2.8) years; $48.4 \%$ of enrollees were boys. The main symptom at first examination was fever (mean temperature $38.2^{\circ} \mathrm{C}\left[\mathrm{SD} 0.6^{\circ} \mathrm{C}\right]$ ). Most children had 
Table 1. Prevalence of IgG against Coxiella burnetii, SFGR, TGR, and STGO in serum samples from febrile children attending Webuye District Hospital, Bungoma, Kenya, November 2011-December 2012*

\begin{tabular}{|c|c|c|c|c|c|}
\hline Antigen type & $\begin{array}{c}\text { Total no. samples } \\
\text { screened }\end{array}$ & No. $(\%)$ screen positive & $\begin{array}{c}\text { Total no. paired } \\
\text { samples }\end{array}$ & $\begin{array}{c}\text { No. }(\%) \text { lgG- } \\
\text { positive† }\end{array}$ & No. (\%) acute infections $\ddagger$ \\
\hline C. burnetii & 364 & $47(12.9)$ & 281 & $10(3.6)$ & $25(8.9)$ \\
\hline SFGR & 364 & $104(28.6)$ & 281 & $23(8.2)$ & $63(22.4)$ \\
\hline TGR & 364 & $6(1.6)$ & 281 & $1(0.4)$ & $3(1.1)$ \\
\hline STGO & 364 & $21(5.8)$ & 281 & $9(3.2)$ & $10(3.6)$ \\
\hline
\end{tabular}

been ill for 2 days before arrival at WDH, and 20\% had been pretreated with an antimalarial drug, an antimicrobial drug, or both. Average time between enrollment and follow-up was 45 (SD 12) days. Overall, 364 convalescentand unpaired acute-phase serum samples were screened; 47 (12.9\%), $104(28.6 \%), 6(1.6 \%)$, and $21(5.8 \%)$ were seropositive for C. burnetii, SFGR, TGR, and STGO, respectively. Of the 364 serum samples, 281 (77.2\%) represented paired acute- and convalescent-phase samples, of which 25 (8.9\%), $63(22.4 \%), 3(1.1 \%)$, and $10(3.6 \%)$ had results indicative of acute C. burnetii, SFGR, TGR, and STGO infection, respectively (Table 1). Endpoints were 400 to $\geq 6,400$ for SFGR, 400 to 1,600 for STGO, and 400 for TGR. Dual infections were noted in $27(9.6 \%)$ of the 281 paired acute- and convalescent-phase samples: STGO and SFGR were found in 7 (2.5\%), C. burnetii and SFGR in 14 (5.0\%), C. burnetii and TGR in $2(0.7 \%)$, and C. burnetii and STGO in $4(1.4 \%)$ samples.

To ensure no cross reactivity of $C$. burnetii- and STGO-positive serum samples, we used Western blot to test the $C$. burnetii-positive serum against STGO proteins. No cross-reactivity was observed with the $C$. burnetii-specific IgG-positive serum and the Orientia-specific recombinant proteins (Figure).

Statistical analyses showed SFGR-infected children were more likely to be girls than boys $(p=0.007)$, indicating sex as a possible risk factor (Table 2). The primary clinical signs of all infections were cough, diarrhea, vomiting, and inability to drink or breastfeed. $C$. burnetii-infected children were more likely than C. burnetii-uninfected children to report cough $(\mathrm{p}=0.018)$. Of the children with rickettsial infections, $81 \%-90 \%$ received antimalarial drugs and $\approx 60 \%$ received antimicrobial drugs; similar proportions were seen for Q fever patients. Virtually all Q fever and rickettsia-infected patients received a diagnosis of malaria by the treating clinician. C. burnetii and SFGR cases were detected throughout the year, with peaks noted in February-June for SFGR and April-July for C. burnetii.

\section{Conclusions}

In this study, the seroprevalence of IgG against SFGR was $28.7 \%$, a finding similar to that in a previous study in Tanzania (11). We observed higher rates $(22.4 \%)$ of acute SFGR infections than were observed among pediatric patients in Tanzania $(\geq 8 \%)$, where similar serologic tools were used to diagnose acute rickettsial infections $(11,12)$. Acute SFGR infections occurred throughout the year, but increases were noted during February-June, months which coincide with the long rainy season in Kenya. Seasonal peaks of SFGR infections coinciding with wetter months have been observed in sub-Saharan

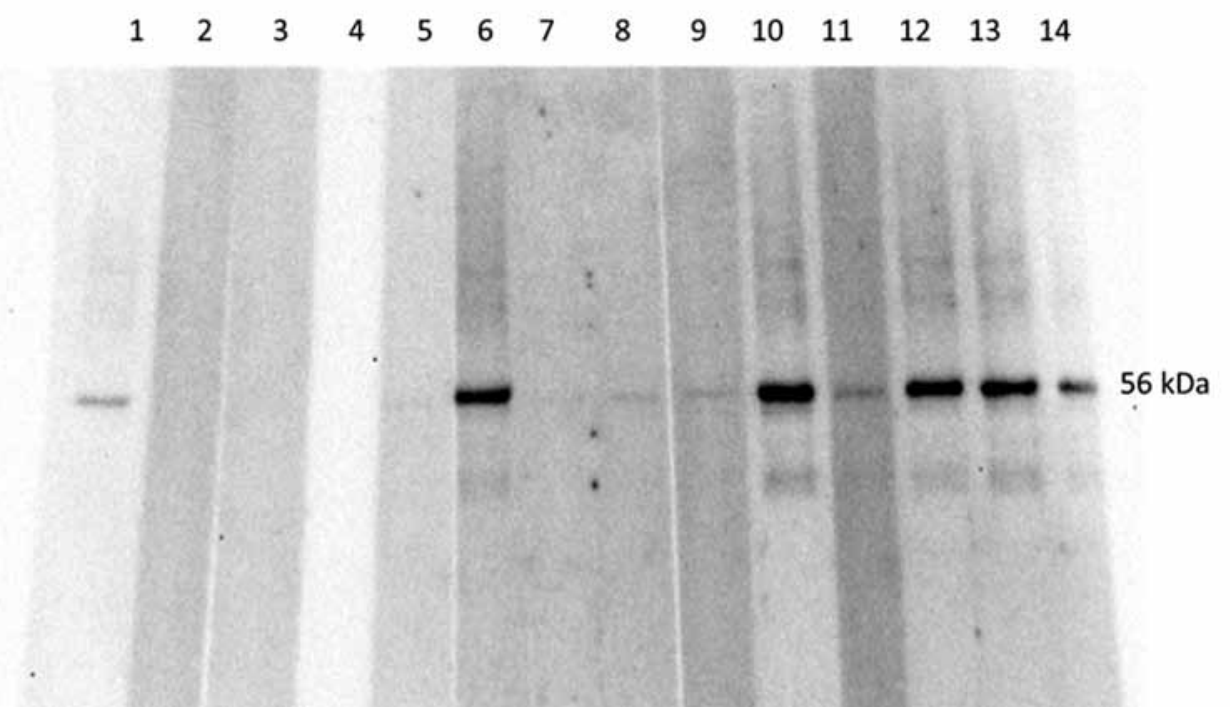

Figure. Western blot analysis, using Orientia $56 \mathrm{Kpr}$ recombinant protein, of serum samples from febrile children in western Kenya, November 2011-December 2012. Lane 1 , positive control; lane 2 , negative control; lanes $3-4$, Coxiella burnetii-positive patients; lane 5, Orientia spp.negative patient; lanes $6-14$, Orientia spp.-positive patients. 
Table 2. Analysis of variables across Coxiella burnetii, SFGR, and STGO infections in febrile children attending Webuye District Hospital, Bungoma, Kenya, November 2011-December 2012*

\begin{tabular}{|c|c|c|c|c|c|c|c|c|c|}
\hline \multirow[b]{2}{*}{ Variable } & \multicolumn{3}{|c|}{ C. burnetii } & \multicolumn{3}{|c|}{ SFGR } & \multicolumn{3}{|c|}{ STGO } \\
\hline & $\begin{array}{l}\text { Positive, } \\
n=25 \dagger\end{array}$ & $\begin{array}{l}\text { Negative, } \\
n=256 \dagger\end{array}$ & $p$ value & $\begin{array}{l}\text { Positive, } \\
n=63 \dagger\end{array}$ & $\begin{array}{l}\text { Negative, } \\
\mathrm{n}=218 \dagger\end{array}$ & $p$ value & $\begin{array}{l}\text { Positive, } \\
\mathrm{n}=10 \dagger\end{array}$ & $\begin{array}{l}\text { Negative, } \\
\mathrm{n}=271 \dagger\end{array}$ & $p$ value \\
\hline Mean age, y (SD) & $3.8(0.48)$ & $4.5(0.18)$ & 0.283 & $3.8(0.35)$ & $4.6(0.19)$ & 0.065 & $4.8(0.87)$ & $4.4(0.17)$ & 0.669 \\
\hline \multicolumn{10}{|l|}{ Sex } \\
\hline $\begin{array}{l}M \\
F\end{array}$ & $\begin{array}{l}39 \\
61\end{array}$ & $\begin{array}{l}47 \\
52\end{array}$ & 0.452 & $\begin{array}{l}31.8 \\
68.2\end{array}$ & $\begin{array}{l}51.1 \\
48.9\end{array}$ & $0.007 \ddagger$ & $\begin{array}{l}20 \\
80\end{array}$ & $\begin{array}{l}47.6 \\
52.4\end{array}$ & 0.086 \\
\hline \multicolumn{10}{|l|}{ Symptom } \\
\hline Rash & 0 & 1.6 & 0.548 & 1.6 & 1.4 & 0.901 & 0 & 1.5 & 0.7 \\
\hline Vomiting & 21.7 & 16.7 & 0.536 & 25.4 & 14.7 & $0.046 \S$ & 30 & 16.6 & 0.269 \\
\hline Cough & 73.9 & 48 & $0.018 \#$ & 54 & 49.1 & 0.495 & 60 & 49.8 & 0.527 \\
\hline Diarrhea & 17.4 & 10.5 & 0.31 & 15.9 & 9.6 & 0.164 & 30 & 10.3 & 0.051 \\
\hline Difficulty breathing & 0 & 1.6 & 0.548 & 1.6 & 1.4 & 0.901 & 0 & 1.5 & 0.7 \\
\hline $\begin{array}{l}\text { Inability to drink or } \\
\text { breastfeed }\end{array}$ & 13 & 7.4 & 0.331 & 9.5 & 7.3 & 0.57 & 10 & 7.8 & 0.795 \\
\hline Admitted to hospital & 30.4 & 23.6 & 0.466 & 20.6 & 25.2 & 0.453 & 10 & 24.7 & 0.286 \\
\hline \multicolumn{10}{|l|}{$\begin{array}{l}\text { Treatment administered at } \\
\text { hospital }\end{array}$} \\
\hline Antimicrobial drug & 73.9 & 54.7 & 0.074 & 61.9 & 59.7 & 0.746 & 50 & 57.2 & 0.505 \\
\hline Antimalarial drug & 82.6 & 81 & 0.851 & 81 & 81.2 & 0.966 & 90 & 80.8 & 0.466 \\
\hline Recovered after treatment & 100 & 92.6 & 0.158 & 98.4 & 92.3 & 0.076 & 100 & 92.7 & 0.372 \\
\hline $\begin{array}{l}\text { Malaria diagnosed by } \\
\text { clinician }\end{array}$ & 100 & 89.8 & 0.094 & 95.2 & 89.1 & 0.138 & 100 & 90.2 & 0.294 \\
\hline \multicolumn{10}{|c|}{$\begin{array}{l}\text { *SFGR, spotted fever group rickettsiae, STGO, scrub typhus group orientiae. } \\
\text { †Values are percentages unless otherwise specified. } \\
\text { †Being a girl was indicated as a possible risk factor for SFGR infection }(p<0.05) \text {. } \\
\text { §Children with SFGR were more likely to report vomiting }(p<0.05) . \\
\text { \#Children with C. burnetii were more likely to report cough }(p<0.05) \text {. }\end{array}$} \\
\hline
\end{tabular}

Africa (3). A higher frequency of acute SFGR was noted in girls than boys and may be related to occupational exposure, as noted among women in Peru (13). TGR rates in our study are comparable to those reported in Tanzania (11).

The seroprevalence of STGO was $5.8 \%$, similar to that reported from a previous study in Kenya (5). Detection of enhanced seroreactivity to scrub typhus suggests acute infections with Orientia spp. Scrub typhus was formerly thought to be geographically restricted to Asia, but the distribution has been redefined by the recent detection of Orientia DNA in mice in Africa; description of scrub typhus-like illnesses in Chile and United Arab Emirates; and discovery of a new species, $O$. chuto, isolated from a patient who had visited Dubai (14).

In addition, the prevalence of antibodies to $C$. burnetii observed in our study is higher $(12.9 \%)$ than that reported for other African countries $(<8 \%)$ but within the range reported among children in Egypt $(10 \%-32 \%)$ (15). Our findings showed a much higher rate $(8.9 \%)$ of acute $\mathrm{Q}$ fever than reported among infants and children in Tanzania (2.6\%) (11). A distinct seasonality was noted with acute $\mathrm{Q}$ fever infections, and this may be related to the parturient season in domestic and wild animals (11). The dual infections with SFGR and STGO and STGO and C. burnetii may be the result of similar risk factors. Additional research is needed to identify the reservoirs and vectors of Orientia spp. in Africa and to identify key risk factors for infection.

\section{Acknowledgment}

We thank the staff of Webuye District Hospital for their assistance in patient management and specimen collection.

This work was supported by the Global Emerging Infections Surveillance and Response System, a Division of the Armed Forces Health Surveillance Center (847705.82000.25GB. A0074), and a pilot grant from Duke Global Health Institute.

Dr. Maina is a postdoctoral research associate at the Naval Medical Research Center. Her research effort is focused on the epidemiological surveillance of emerging infectious diseases in multihost(s) systems in an effort to identify the arthropod vectors, reservoir hosts, and risk factors associated with these diseases.

\section{References}

1 Knobel DL, Maina AN, Cutler SJ, Ogola E, Feikin DR, Junghae M, et al. Coxiella burnetii in humans, domestic ruminants, and ticks in rural western Kenya. Am J Trop Med Hyg. 2013;88:513-8. http://dx.doi.org/10.4269/ajtmh.12-0169

2. Maina AN, Knobel DL, Jiang J, Halliday J, Feikin DR, Cleaveland S, et al. Rickettsia felis infection in febrile patients, western Kenya, 2007-2010. Emerg Infect Dis. 2012;18:328-31. http://dx.doi.org/10.3201/eid1802.111372

3. Mediannikov O, Socolovschi C, Edouard S, Fenollar F, Mouffok N, Bassene H, et al. Common epidemiology of Rickettsia felis infection and malaria, Africa. Emerg Infect Dis. 2013;19:1775-83. http://dx.doi.org/10.3201/eid1911.130361

4. Parola P. Rickettsia felis: from a rare disease in the USA to a common cause of fever in sub-Saharan Africa. Clin Microbiol Infect. 2011;17:996-1000. http://dx.doi.org/10.1111/ j.1469-0691.2011.03516.x 
5. Thiga JW, Mutai BK, Eyako WK, Ng'ang'a Z, Jiang J, Richards AL, et al. High seroprevalence of antibodies against spotted fever and scrub typhus bacteria in patients with febrile Illness, Kenya. Emerg Infect Dis. 2015;21:688-91. http://dx.doi.org/ 10.3201/eid2104.141387

6. DePuy W, Benka V, Massey A, Deem SL, Kinnaird M, O’Brien T, et al. Q fever risk across a dynamic, heterogeneous landscape in Laikipia County, Kenya. EcoHealth. 2014;11:429-33. http://dx.doi.org/10.1007/s10393-014-0924-0

7. O’Meara WP, Mott JA, Laktabai J, Wamburu K, Fields B, Armstrong J, et al. Etiology of pediatric fever in western Kenya: a case-control study of falciparum malaria, respiratory viruses, and streptococcal pharyngitis. Am J Trop Med Hyg. 2015;92:1030-7. http://dx.doi.org/10.4269/ajtmh.14-0560

8. Graf PC, Chretien JP, Ung L, Gaydos JC, Richards AL. Prevalence of seropositivity to spotted fever group rickettsiae and Anaplasma phagocytophilum in a large, demographically diverse US sample. Clin Infect Dis. 2008;46:70-7. http://dx.doi.org/10.1086/524018

9. Jiang J, Marienau KJ, May LA, Beecham HJ III, Wilkinson R, Ching WM, et al. Laboratory diagnosis of two scrub typhus outbreaks at Camp Fuji, Japan in 2000 and 2001 by enzyme-linked immunosorbent assay, rapid flow assay, and Western blot assay using outer membrane 56-kD recombinant proteins. Am J Trop Med Hyg. 2003;69:60-6.

10. Richards AL, Soeatmadji DW, Widodo MA, Sardjono TW, Yanuwiadi B, Hernowati TE, et al. Seroepidemiologic evidence for murine and scrub typhus in Malang, Indonesia. Am J Trop Med Hyg. 1997;57:91-5.
11. Prabhu M, Nicholson WL, Roche AJ, Kersh GJ, Fitzpatrick KA, Oliver LD, et al. Q fever, spotted fever group, and typhus group rickettsioses among hospitalized febrile patients in northern Tanzania. Clin Infect Dis. 2011;53:e8-15. http://dx.doi.org/ 10.1093/cid/cir411

12. Crump JA, Morrissey AB, Nicholson WL, Massung RF, Stoddard RA, Galloway RL, et al. Etiology of severe non-malaria febrile illness in northern Tanzania: a prospective cohort study. PLoS Negl Trop Dis. 2013;7:e2324. http://dx.doi.org/10.1371/ journal.pntd.0002324

13. Schoeler GB, Moron C, Richards A, Blair PJ, Olson JG Human spotted fever rickettsial infections. Emerg Infect Dis. 2005;11:622-4. http://dx.doi.org/10.3201/eid1104.040287

14. Cosson JF, Galan M, Bard E, Razzauti M, Bernard M, Morand S, et al. Detection of Orientia sp. DNA in rodents from Asia, West Africa and Europe. Parasit Vectors. 2015;8:172. http://dx.doi.org/10.1186/s13071-015-0784-7

15. Vanderburg S, Rubach MP, Halliday JE, Cleaveland S, Reddy EA, Crump JA. Epidemiology of Coxiella burnetii infection in Africa: a OneHealth systematic review. PLoS Neg1 Trop Dis. 2014;8:e2787. http://dx.doi.org/10.1371/journal.pntd.0002787

Address for correspondence: Alice N. Maina, Viral and Rickettsial Diseases Department, Naval Medical Research Center, 503 Robert Grant Ave, Silver Spring, MD 20910, USA: email: alice.n.maina.ctr@mail.mil

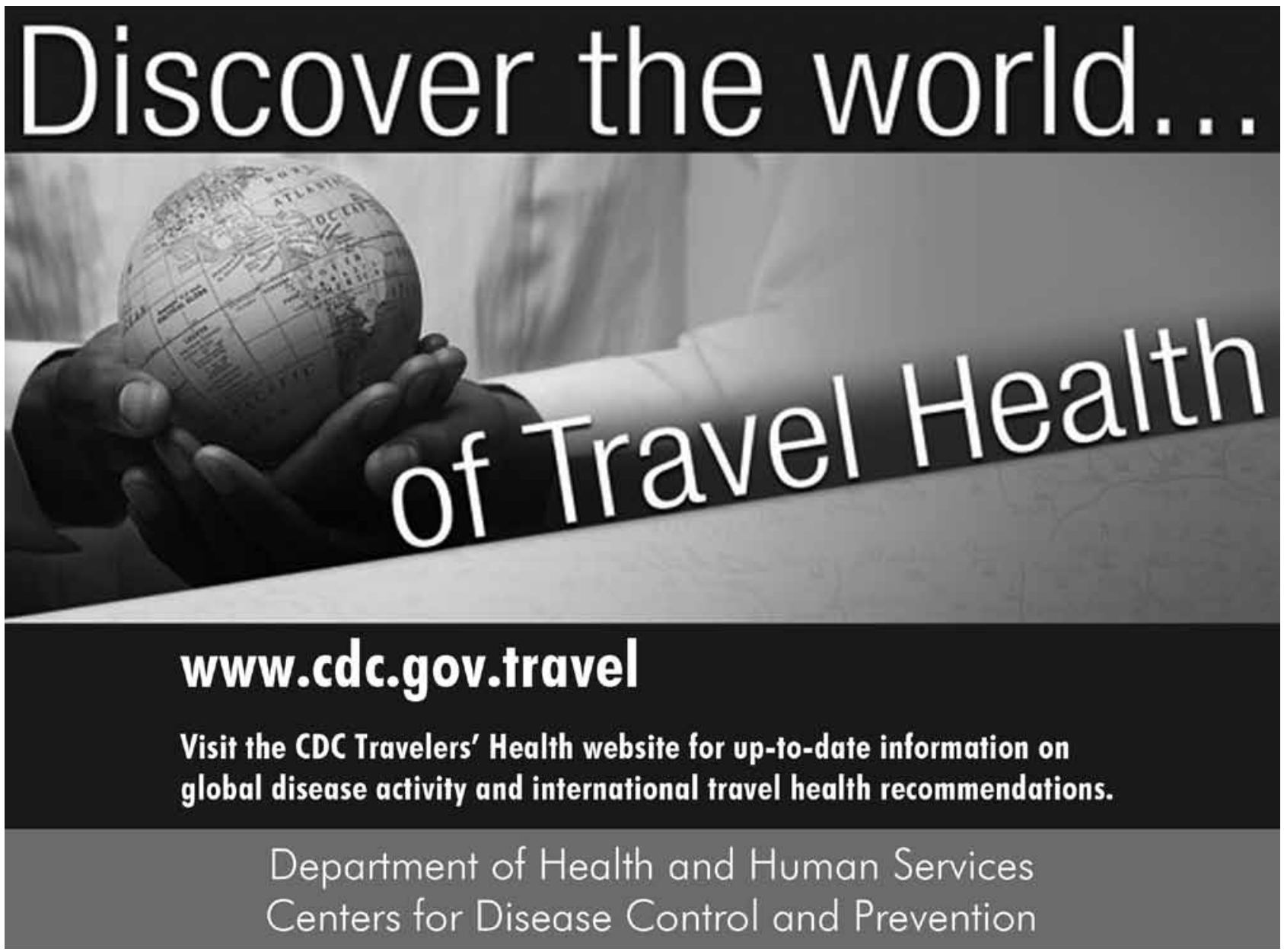

